Caring : Jurnal Keperawatan

Vol.8, No. 1, Maret 2019, pp. $01-08$

ISSN 1978-5755 (Online)

DOI: 10.29238

Journal homepage: http://e-journal.poltekkesjogja.ac.id/index.php/caring/

\title{
Hubungan peranan teman sebaya dengan perkembangan sosial emosional siswa-siswi kelas X di SMK Negeri 2 Sewon Bantul Yogyakarta
}

\section{The corelation between friends relationship and the social empowerment of students in SMK Negeri 2 Sewon Bantul Yogyakarta}

\author{
Evi Suryandari ${ }^{1 a^{*}}$, Sulistiyawati ${ }^{1}$, Lia Endriyani ${ }^{1}$ \\ ${ }^{1}$ Prodi Ilmu Keperawatan Universitas Alma Ata Yogyakarta \\ a evisuryandari10@gmail.com
}

HIGHLIGHTS

\section{ARTICLE INFO}

\section{Article history}

\section{Keywords:}

Youth

Emotional Social

Peers

\section{Kata kunci:}

Remaja

Sosial emosional

Teman sebaya

\section{A B STR ACT / A B STR AK}

Teenagers are the time to mature with the rapid development of physical, cognitive, emotional and social. Not all adolescents get through smoothly. Emotional social problems marked aggressiveness and delinquency. During 2016 in DIY recorded 43 cases of student brawl, perpetrators of children aged 14-18 years. One of the factors that influence is peers. Teens spend a lot of time hanging out with their peers, so peers are influential in emotional social development. To know the relationship of peer role with emotional social development of students at SMK Negeri 2 Sewon Bantul Yogyakarta. The design of this research is analytic descriptive with cross sectional approach. The sampling condition used cluster random sampling method with 107 student sample. The research instrument used is peer role questionnaire and emotional social development questionnaire. Bivariate statistical test using Pearson. The majority of respondents were women of 81 people $(75.7 \%), 16$ years of age 77 people (72\%), peer role was 81 people $(75.7 \%)$, and emotional social development both 101 people $(94.4 \%)$. The role of peers is with the emotional social development both $76(71.0 \%)$. Result of bivariate test analysis obtained $p$ value $=0,028$ and correlation coefficient value 0,213 . There is a significant relationship between the role of peers with emotional social development in the students at SMK Negeri 2 Sewon Bantul Yogyakarta.

Remaja ialah masa menuju dewasa dengan pesatnya perkembangan fisik, kognitif, emosional dan sosial.Tidak semua remaja dapat melewati dengan mulus. Masalah sosial emosional ditandai agresifitas dan kenakalan.Selama 2016 di DIY tercatat 43 kasus tawuran pelajar, pelaku anak usia 14-18 tahun. Salah satu faktor yang mempengaruhi ialah teman sebaya.Remaja banyak menghabiskan waktu berkumpul bersama teman sebayanya, sehingga teman sebaya berpengaruh dalam perkembangan sosial emosional. Mengetahui hubungan peranan teman sebaya dengan perkembangan sosial emosional siswa-siswi di SMK Negeri 2 Sewon Bantul Yogyakarta. Desain penelitian ini ialah deskriptif analitik dengan pendekatan cross sectional. Perhituangan sampel menggunakan metode cluster random sampling dengan jumlah sampel 107 siswa. Instrument penelitian yang digunakan ialah kuesioner peran teman sebaya dan kuesioner 
perkembangan sosial emosional.Uji statistik bivariat menggunakan Pearson. Mayoritas responden berjenis kelamin perempuan 81 orang $(75,7 \%)$, berusia 16 tahun 77 orang $(72 \%)$, peranan teman sebaya sedang 81 orang $(75,7 \%)$, dan perkembangan sosial emosional baik 101 orang $(94,4 \%)$. Peranan teman sebaya sedang dengan perkembangan sosial emosional baik 76 (71,0\%). Hasil analisis uji bivariat diperoleh nilai $p$ value $=0,028$ dan nilai koefisien korelassi 0,213 . Terdapat hubungan signifikan antara peranan teman sebaya dengan perkembangan sosial emosional pada siswa-siswi di SMK Negeri 2 Sewon Bantul Yogyakarta

Copyright (C) 2019 Caring : Jurnal Keperawatan. All rights reserved

\section{${ }^{\star}$ Corresponding Author:}

Evi Suryandari,

Program Studi Ilmu Keperawatan Universitas Alma Ata Yogyakarta,

Jln. Brawijaya No.99, Jadan, Tamantirto, Kasihan, Bantul, D I Yogyakarta

\section{PENDAHULUAN}

Remaja merupakan masa peralihan dari anak-anak menuju dewasa yang ditandai dengan kematangan fisik, kognitif, sosial dan emosional. Masa remaja terbagi menjadi tiga fase, yaitu: fase remaja awal (usia 11-14 tahun), fase remaja pertengahan (usia 14-16 tahun), fase remaja akhir (usia 17-20 tahun) (1). Umumnya masa remaja pada remaja putri mulai dan berakhir lebih awal dibandingkan remaja putra (2) (3).Fase ini juga dimulainya tanggung jawab dan peran remaja dalam masyarakat (4).

Masa remaja membuat mereka mencoba untuk tanggung jawab yang berhubungan dengan kemandirian.Namun ada ketakutan tersendiri dari remaja karena untuk mendapatkan kematangan identitas, remaja harus mampu melewati tugas perkembangan setiap fase dengan baik. Rasa kemandirian memerlukan perkembangan hubungan sosial diluar keluarga sehingga remaja dapat mengenali peranya dalam masyarakat.Masa remaja merupakan masa kemampuan dan kesiapan bersosialisasi yang tidak bisa diragukan.Syarat kesiapan interpersonal remaja didapat dari rasa cinta yang diberikan keluarga, penerimaan teman sebaya, dan beberapa teman dekat (2).

Menurut World Health Organitations (WHO) pada tahun 2010 jumlah remaja di dunia mencapai $\pm 1,2$ milyar remaja atau seperlima dari total penduduk dunia ialah remaja berusia 10-19 tahun dan sekitar 900 juta remaja berada dinegara berkembang (5). Sementara berdasarkan pusat data dan informasi, Kemenkes RI tahun 2016 jumlah penduduk indonesia sebanyak 258,7 juta jiwa, dan 66,3 juta jiwa ialah usia remaja (6). Usia 10-19 di Yogyakarta sendiri tercata sebanyak 68,759 jiwa (7). Jumlah besaranya prevalensi usia remaja akan berpengaruh pada pembangunan aspek sosial, ekonomi, maupun demografi baik masa sekarang ataupun yang akan datang.

Tingginya prevalensi usia remaja menjadi salah satu penyebab tingginya masalah kenakalan pada anak remaja sehingga penting adanya perhatian lebih pada masalah sosial emosional untuk remaja. Riset Kesehatan Dasar tahun 2013, umur $\geq 10$ tahun memiliki kebiasaan menghisap rokok setiap hari adalah 12,3 batang atau setara satu bungkus dan prevalensi usia $\geq 15$ tahun menghisap rokok cenderung meningkat dari Riskesdas 2007 (34,2\%), Riskesdas 2010 (34,7\%) dan Riskesdas 2013 (36,3\%). DIY sendiri menempati jumlah perokok harian dengan jumlah $21,2 \%$. (8). DIY selain tercatat sebagai daerah yang memiliki prevalensi remaja merokok dan gangguan mental emosional tinggi.Selain itu menjadi wilayah dengan kenakalan remaja yang tinggi.Seperti bolos sekolah, tawuran, ugal-ugalan, alkohol dan hamil diluar pernikahan. Selama tahun 2016, jumlah kasus tawuran pelajar di DIY sebanyak 43 kasus dan pelaku tawuran berkisar anak usia 14-18 tahun (9).

Perilaku negatif dan kenakalan yang dilakukan oleh remaja merupakan bentuk penyimpangan. Hal ini terjadi karena suatu tahap perkembangan yang tidak mampu di 
selesaikan oleh remaja. Kartono mengatakan, kenakalan remaja (juvenile delinquency) ialah bentuk patologis sosial karena akibat pengabaian sosial (10). Semestinya saat ini remaja sudah mampu melewati tugas-tugas perkembangan dengan baik, pasalnya hal tersebut bias menjadi landasan remaja sehingga mampu menghadapi dan mengontrol sosial emosionalnya (11).

Perkembangan sosial-emosional dalam konteks remaja awal adalah suatu perubahan berfikir tentang sekelilingnya dengan atau tanpa tingkah laku sebagai wujud ekspresi emosi. Mengarah pada hubugan seseorang dengan orang lain karena adanya sebuah dorongan rasa ingin tahu dari sekelilingnya dan bagaimana orang-orang disekitarnya akan berpengaruh terhadap dirinya (12).Perkembangan sosial-emosional remaja dipengaruhi oleh 2 faktor yaitu faktor internal meliputi pengaruh yang muncul dalam diri sendiri (keadaan fisik, struktur syaraf, kelenjar, sistem otot, kesehatan, penyakit, dan lain-lain) dan faktor eksternal yang berasal dari luar diri remaja (lingkungan keluarga, teman sebaya dan kebudayaan) (1).

Teman berperan memenuhi kebutuhan sosial selama masa remaja. Setiap orang memiliki kebutuhan sosial yang mendasar, yaitu kebutuhan akan kelembutan (kelekatan yang aman), teman bermain, penerimaan sosial, keintiman dan hubungan seksual. Terpenuhinya beberapa kebutuhan sosial dasar akan sangan menentukan kesejahteraan emosional remaja. Seperti contohnya, ketika kebutuhan memiliki teman bermain tidak terpenuhi remaja akan merasa tertekan dan bosan (13).

Berdasarkan hasil studi pendahuluan dengan wawancara yang dilakukan kepada 10 siswa SMK Negeri 2 Sewon Bantul Yogyakarta terdiri dari 4 laki-laki dan 6 perempuan terkait perkembangan sosial emosional diperoleh hasil, 8 siswa mengatakan senang berkumpul, bermain bersama dan mudah bergaul dengan teman baru yang asyik dan suka bercanda. Dua siswa mengatakan berkumpul dengan teman hanya saat disekolah, tidak mudah bergaul dengan orang baru dan memerlukan waktu untuk bisa akrab dengan teman atau orang baru. Terkait emosional, ketika marah 2 siswa mengatakan memilih untuk tidur, 5 siswa mengatakan memilih untuk pergi bermain dengan sahabat, 2 siswa mengatakan memilih berdiam diri dan 1 siswa mengatakan memilih meluapkanemosinya dengan memukul teman.

Berdasarkan uraian latar belakang di atas peneliti tertarik untuk menganalisis lebih lanjut mengenai hubungan peranan teman sebaya dengan perkembangan sosial emosional pada anak usia remaja.

\section{BAHAN DAN METODOLOGI PENELITIAN}

Desain penelitian ini menggunakan deskriptif analitik dengan pendekatan cross sectional. Penelitian ini bertempat di SMK N 2 Sewon Bantul Yogyakarta yang dilaksananan pada bulan Mei 2018.Populasi penelitian ini ialah siswa-siswi kelas X di SMK N 2 Sewon Bantul Yogyakarta yang berjumlah sebanyak 235 orang. Perhituangan sampel menggunakan metode cluster random sampling dengan jumlah sampel 107 siswa. Instrument penelitian yang digunakan ialah kuesioner peran teman sebaya dan kuesioner perkembangan sosial emosional.Uji statistik bivariat menggunakan Pearson. 


\section{HASIL DAN PEMBAHASAN}

Tabel 1. Distribusi frekuensi karakteristik responden berdasarkan karakteristik siswa (jenis kelamin dan usia) di SMK Negeri 2 Sewon Bantul Yogyakarta, bulan Mei 2018

Karakteristik

responden

Frekuensi (f) Persentase (\%)

\begin{tabular}{ccc}
\hline $\begin{array}{c}\text { Jenis kelamin } \\
\text { Laki-laki }\end{array}$ & 26 & 24,3 \\
Perempuan & 81 & 75,7 \\
\hline Usia & 0 & 0 \\
14 tahun & 30 & 28 \\
15 tahun & 77 & 72 \\
16 tahun & 107 & 100
\end{tabular}

Sumber: Data Primer 2018

Tabel 1 diketahui bahwa karakteristik siswa kelas $X$ di SMK Negeri 2 Sewon Bantul Yogyakarta berjenis jenis kelamin laki-laki 26 siswa $(24,3 \%)$ perempuan 81 siswa $(75,7)$, dan mayoritas berusia 16 tahun sebanyak 77 siswa (72\%), 15 tahun sebanyak 30 siswa $(28 \%)$.

Tabel 2. Distribusi Frekuensi Peranan Teman Sebaya Siswa-siswi di SMK Negeri 2 Sewon Bantul Yogyakarta, bulan Mei 2018

\begin{tabular}{cccc}
\hline Peranan teman sebaya & Frekuensi (f) & Persentase (\%) \\
\hline $26-46$ & Rendah & 3 & 2,8 \\
$47-68$ & Sedang & 81 & 75,7 \\
$69-89$ & Tinggi & 23 & 21,5 \\
\hline Total & & 107 & 100 \\
\hline
\end{tabular}

Sumber: Data Primer 2018

Tabel 2 diketahui bahwa sebagian besar siswa memiliki peranan teman sebaya sedang sebayak 81 siswa $(75,7 \%)$, peranan teman sebaya tinggi sebanyak 23 siswa $(21,5 \%)$, peranan teman sebaya rendah sebanyak 3 siswa $(2,8 \%)$.

Tabel 3. Distribusi Frekuensi Perkembangan Sosial Emosional Siswa-siswi di SMK Negeri 2 Sewon Bantul Yogyakarta, Bulan Mei 2018

\begin{tabular}{cccc}
\hline \multicolumn{2}{c}{ Perkembangan sosial emosional } & Frekuensi (f) & Persentase (\%) \\
\hline $50-59$ & Kurang & 0 & 0 \\
$60-69$ & Cukup & 6 & 5,6 \\
$70-90$ & Baik & 101 & 94,4 \\
\hline Total & & 107 & 100 \\
\hline
\end{tabular}

Sumber: Data Primer 2018

Tabel 3 diketahui bahwa sebagian besar memiliki perkembangan sosial emosional baik sebayak 101 siswa $(94,4 \%)$, perkembangan sosial emosional cukup sebanyak 6 siswa $(5,6 \%)$.

Tabel 4. Tabulasi silang antara enis kelamin dengan perkembangan sosial emosional siswasiswi di SMK Negeri 2 Sewon Bantul Yogyakarta bulan Mei 2018

\begin{tabular}{ccccccccccc}
\hline \multirow{2}{*}{ Jenis Kelamin } & \multicolumn{9}{c}{ Perkembangan Sosial Emosional } & \multirow{2}{*}{ P - Value } \\
\cline { 2 - 9 } & Kurang & \multicolumn{1}{c}{ Cukup } & \multicolumn{3}{c}{ Baik } & Jumlah & \\
\hline & f & $\%$ & f & $\%$ & f & $\%$ & f & $\%$ & \\
\hline Laki-laki & 0 & 0 & 1 & 0,9 & 25 & 23,4 & 26 & 24,3 & 0,657 \\
Perempuan & 0 & 0 & 5 & 4,7 & 76 & 71,0 & 81 & 75,7 & \\
\hline Total & 0 & 0 & 6 & 5,6 & 101 & 94,4 & 107 & 100 & \\
\hline
\end{tabular}

Sumber: Data Primer (2016) 
Tabel 4 diperoleh hasil bahw siswa yamng memiliki perkembangan sosial emosional baik dengan jenis kelamin perempuan sebanyak 76 orang $(71,0 \%)$, dan siswa yang memiliki perkembangan sosial emosional cukup dengan jenis kelamin laki-laki sebanyak 1 orang (0,9\%). Berdasarkan hasil uji statistik menggunakan uji Pearson Produce Moment diperoleh hasil $p$ value 0,657 yang artinya lebih dari 0,05 , jadi tidak ada hubungan antara jenis kelami dengan perkembagan sosial emosional pada siswa-siswi kelas $\mathrm{X}$ di SMK $\mathrm{N}$ 2 Sewon Bantul Yogyakarta.

Tabel 5. Tabulasi silang peranan teman sebaya dengan perkembangan sosial emosional siswasiswi di SMK Negeri 2 Sewon Bantul Yogyakarta bulan Mei 2018

\begin{tabular}{|c|c|c|c|c|c|c|c|c|c|}
\hline \multirow{3}{*}{$\begin{array}{l}\text { Peranan } \\
\text { Teman } \\
\text { Sebaya }\end{array}$} & \multicolumn{7}{|c|}{ Perkembangan Sosial Emosional } & \multirow{3}{*}{$\begin{array}{c}\mathbf{P} \text { - } \\
\text { Value }\end{array}$} & \multirow{3}{*}{$\begin{array}{c}\text { Koefisiensi } \\
\text { korelasi }\end{array}$} \\
\hline & Kurang & \multicolumn{2}{|c|}{ Cukup } & \multicolumn{2}{|c|}{ Baik } & \multicolumn{2}{|c|}{ Jumlah } & & \\
\hline & f $\%$ & f & $\%$ & f & $\%$ & f & $\%$ & & \\
\hline Rendah & 0 & 0 & 0 & 3 & 2,8 & 3 & 2,8 & 0,028 & 0,213 \\
\hline Sedang & 0 & 5 & 4,7 & 76 & 71,0 & 81 & 75,7 & & \\
\hline Tinggi & 0 & 1 & 0,9 & 22 & 20,6 & 23 & 21,5 & & \\
\hline Total & 0 & 6 & 5,6 & 101 & 94,4 & 107 & 100 & & \\
\hline
\end{tabular}

Sumber: Data Primer (2016)

Tabel 1.5 diperoleh hasil bahwa siswa yang memiliki peranan teman sebaya sedang dengan perkembangan sosial emosional baik sebanyak 76 orang $(71,0 \%)$, dan siswa yang memiliki peranan teman sebaya tinggi dengan perkembangan sosial emosional baik sebanyak 22 orang (20,6\%).

Berdasarkan hasil uji statistik menggunakan uji Pearson Produce Moment diperoleh hasil $p$ value 0,028 yang artinya lebih dari 0,05 , jadi hipotesis penelitian diterim bahwa terdapat hubungan antara peranan teman sebaya dengan perkembagan sosial emosional pada siswa-siswi kelas X di SMK N 2 Sewon Bantul Yogyakarta. Keeratan hubungan sebesar 0,213 masuk dalam rentang 0,20-0,399 yang berarti tingkat keeratan hubungan antar variable dalam kategori rendah.

Berdasarkan Tabel 1.1 diketahui bahwa karakteristik siswa kelas $X$ di SMK Negeri 2 Sewon Bantul Yogyakarta didominasi oleh remaja perempuan 81 siswa dibandingkan remaja laki-laki. Secara kondisi emosional tidak ada perbedaan yang berarti antara remaja laki-laki dan remaja perempuan, dikarenakan remaja laki-laki dan perempuan sama-sama mengalami ketegangan emosi, tekanan sosial, dan menghadapi keadaan baru yang berbeda dengan masa kanak-kanak (1).Sejalan dengan hasil penelitian Zahra dkk (2013) menunjukan bahwa tingkat kematangan emosi remaja perempuan tidak lebih tinggi dari pada laki-laki (14).

Karakteristik responden berdasarkan usia, usia 16 tahun menempati persentase terbanyak. Usia remaja di kenal memiliki gejolak emosi yang tidak terkendali dan kuat, namun seiring perubahan usia gejolak emosi remaja akan turut mengalami perubahan menuju lebih baik. Menurut Gesell dalam Hurlock (2010) remaja pada 14 tahun sering tidak bias menyembunykan emosi yang meledak-ledak, terkadang sangan marah, namun terkadang sangat sedih, dan tidak ada usaha untuk mengendalikan emosi, tetapi cenderung mengikuti perasaan emosi. ketika usia 16 tahun remaja akan menunjukan sikap tidak perduli tidak mengikuti perasaan emosinya (1). Hasil penelitian ini didukung oleh penelitian Curtis (2015) remaja secara kognitif penuh keformalan, namun pada remaja mulai muncul kemampuan penalaran secara kompleks, abstrak dan logis (15). Oleh karenanya tekanan atau tuntutan yang dirasakan saat usia remaja akan berangsur berkurang seiring bertambahnya usia. 
Berdasarkan Tabel 4.2 diketahui bahwa sebagian besar siswa memiliki peranan teman sebaya sedang sebayak 81 siswa, peranan teman sebaya tinggi sebanyak 23 siswa , peranan teman sebaya rendah sebanyak 3 siswa. Hal ini dapat diinterpertasikan bahwasanya mayoritas siswa memiliki penanan teman sebaya dalam karegori sedang.Senada dengan Hurlock (1978) bahwasanya saat bergaul dengan teman sebaya seorang siswa mempelajari sikap sosial yang tepat dan selain itu persahabatan yang terjalin memberikan kepuasan emosional tersendiri. Hal ini didukung hasil penelitian Rahmawati (2015) bahwa pergaulan teman sebaya memiliki pengaruh yang signivikan terhadap kecerdasan emosional siswa sebesar 24,7\% (16).

Berdasarkan Tabel 1.3 diketahui bahwa sebagian besar memiliki perkembangan sosial emosional baik sebayak 101 siswa, perkembangan sosial emosional cukup sebanyak 6 siswa.Dapat diinterpretasikan bahwa sebagian besar siswa memiliki perkembangan sosial yang baik. Hal ini sejalan dengan hasil penelitian Hastuti (2014) yang menyatakan bahwa penyesuaian sosial yang baik berhubungan dengan bagaimana individu berinteraksi sosial dalam lingkunganya. Interaksi sosial dalam konteks penelitian ini ialah interaksi teman sebaya meberikan kontribusi penuh dalam keberhasilan penyesuaian sosial remaja dikarenakan waktu mereka lebih banyak dihabiskan berada diluar rumah bersama teman sebaya (17).

Tabel 1.4 diperoleh hasil bahwa siswa yamng memiliki perkembangan sosial emosional baik dengan jenis kelamin perempuan sebanyak 76 orang, dan siswa yang memiliki perkembangan sosial emosional cukup dengan jenis kelamin laki-laki sebanyak 1 orang. Hal ini sejalan dengan penelitian Wesley (2011) yang menunjukan bahwa ada perbedaan fungsi sosio-emosional antara remaja laki-laki dan peremuan, dimana remaja permpuan mempunyai kemampuan sosio-emosional yang tinggi dibandingkan kempuan laki-laki, khususnya pada aspek regulasi diri dan kompetensi sosial (18).

Berdasarkan hasil uji statistik menggunakan uji Pearson Produce Moment diperoleh hasil $p$ value 0,657 yang artinya lebih dari 0,05 , jadi tidak ada hubungan antara jenis kelami dengan perkembagan sosial emosional pada remaja kelas X di SMK N 2 Sewon Bantul Yogyakarta.Senada dengan hasil penelitian Zahra (2013) yang menyatakan bahwa tingkat kematangan emosi remaja perempuan tidak lebih tinggi dari pada laki-laki yang artinya permpuan dan laki-laki memiliki tingkat kematangan emosi yang setara (14). Sehingga dapat disimpulkan bahwa perbedaan jenis kelamin tidak memiliki hubungan atau tidak mempengaruhi perkembangan sosial emosional pada remaja, melainkan perkembangan sosial emosional juga dipengaruhi oleh banyak factor lain selain jenis kelamin.

Berdasarkan Tabel 1.5 diperoleh hasil siswa yang memiliki peranan teman sebaya sedang dengan perkembangan sosial emosional baik sebanyak 76 orang, dan siswa yang memiliki peranan teman sebaya tinggi dengan perkembangan sosial emosional baik sebanyak 22 orang. Hasil uji statistik menggunakan uji Pearson Produce Moment diperoleh hasil $p$ value 0,028 yang artinya lebih dari 0,05 , jadi hipotesis penelitian diterima bahwa terdapat hubungan antara peranan teman sebaya dengan perkembagan sosial emosional pada remaja kelas X di SMK N 2 Sewon Bantul Yogyakarta. Keeratan hubungan sebesar 0,213 masuk dalam rentang 0,20-0,399 yang berarti tingkat keeratan hubungan antar variable dalam kategori rendah. Hal ini dapat di interpretasikan bahwa penanan teman sebaya memiliki pengaruh terhadap perkembangan sosial emosional remaja, akan tetapi pengaruhnya rendah terhadap perkembangan sosial emosional remaja.

Hal tersebut sejalan dengan hasil penelitian Asyhari (2017) yang menyatakan bahwa terdapat hubungan antara peranan kelompok teman sebaya dengan kemampuan perkembangan psikososial remaja (19). Hastuti (2014) menyakatan bahwa peranan teman sebaya memiliki pengaruh yang signifikan dan menunjukan hubungan yang positif terhadap kemampuan penyesuaian sosial remaja (17).Adanya hububungan antara peran teman sebaya juga didukung penelitian Wahyuni (2016) menyatakan bahwa 
dukungan sosial teman sebaya perpengaruh secara signifikan dan positif terhadap kemampuan bersosialisasi siswa, semakin tinggi dukungan sosial teman sebaya maka akan semakin tinggi kemampuan bersosialisasi siswa, begitu sebaliknya (20). Emosi merupakan perasaan yang bersemayam dalam diri seseorang yang memberi warna pada kehidupan. berupa perilaku atau ekspresi Hal ini senada dengan penelitian Andriani dkk (2014) yang menyatakan bahwa interaksi teman sebaya memiliki penagaruh sebesar $13,5 \%$ terhadap kecerdasan emosional peserta didik (21).

Teman sebaya tidak dapat dipisahkan dari masa remaja, dimana masa remaja banyak dihabiskan oleh individu diluar rumah untuk berkumpul bersama temannya. Hasil keeratan hubungan sebesar 0,213 masuk dalam rentang 0,20-0,399 hal tersebut dinterpretasikan bahwa teman sebaya memiliki hubungan terhadap perkembangan sosial emosional remaja dengan pengaruh yang rendah. Artinya perkembangan sosial emosional remaja dipengaruhi oleh faktor lain selain peranan teman sebaya. Hal ini didukung hasil penelitian Hasatuti (2014) yang menyatakan bahwa interaksi teman sebaya memiliki sumbangan efektif sebesar $25,8 \%$ terhadap penyesuaian sosial pada remaja siswa SMP N 3 Surakarta yang sisanya dipengaruhi oleh variable lain seperti kondisi fisik, kematangan emosi, budaya dan intelektual (17).

Hal tersebut dapat menjalaskan dalam penelitian ini diperolah hasil siswa yang memiliki peranan teman sebaya sedang dengan perkembangan sosial emosional baik sebanyak 76 orang karena perkembangan sosial emosional remaja tidak hanya dipengaruhi oleh teman sebaya.Senada dengan Teori Keperawatan Model Sistem Perilaku Johnson bahwa perikalu memiliki fungsi "membedakan dan membatasi interaksi seseorang dengan lingkungan dan menunjukan suatu hubungan dari orang tersebut dengan benda, peristiwa, dan keadaan dalam lingkungannya" (22). Saat sistem perilaku di kerjakan secara seimbang dan stabil maka akan tercapai individu yang produktif. Sebaliknya, apabila tidak tercapai keseimbangan dan kestabilan dapat memunculkan tekanan dan pengruh buruk terhadap hubungan antara subsistem atau hubungan manusia dengan lingkungan baik eksternal maupun internal. Jadi apa bila tidak ada keseimbangan atara interaksi individu (remaja) dengan lingkungan (teman sebaya) maka perilaku yang buruk dapat diprediksi menjadi maslah pada remaja atau tidak tercapainya kematangan perkembangan sosial emosional.

\section{KESIMPULAN}

Data yang diperoleh dari hasil analisa diatas dapat ditarik kesimpulan terdapat hubungan peranan teman sebaya dengan perkembangan sosial emosional siswa-siswi di SMK Negeri 2 Sewon Bantul Yogyakarta dengan $p$ value $0,028<0.05$ dan nilai koefisien korelasi 0,213 (rentang 0,200-0,399, korelasi rendah).Sebagian bessar responden berjenis kelamin peren puan dengan usia 16 tahun. Peranan teman sebaya berada pada kategori sedang dan perkembangan sosial emosional dalam kategori baik. Mayoritas responden memiliki peranan teman sebaya sedang dengan perkembangan sosial emosional baik sebanya 76 orang.Diharapkan penelitian ini dapat menjadi bahan kajian bagi mahasiswa, dosen, profesi keperawatan anak, guru bimbingan konseling supaya tercapai perkembangan sosial emosional yang optimal. Serta dapat saling melengkapi penemuan penemuan ilmu baru dalam konteks perkembangan sosial emosional remaja tidak hanya pada fase remaja pertengahan namun pada fase-fase yang lain.

\section{DAFTAR PUSTAKA}

1. Hurlock. Psikologi Perkembangan Suatu Pendekatan Sepanjang Rentang Kehidupan. Jakarta: Erlangga. 2010

2. Wong. Buku Ajar Keperawatan Pediatrik. Jakarta: EGC.2009

3. Soetjiningsih. Tumbuh Kembang Anak. Jakarta:EGC. 2016 
4. Potter \& Perry. Buku Ajar Fundamental Keperawatan. Jakarta: EGC.2005

5. BKKBN \& WHO. Kajian profil penduduk remaja.2011. Available from: www.bkkbn.go.id. Diakses Tanggal13 Oktober 2017

6. KEMENKES RI. Profil Kesehatan Indonesia. 2016. Available from: www.depkes.go.id/.../profil-kesehatan-indonesia/Profil-Kesehatan-Indonesia-2016.pdf. Diakses Tanggal 2 Januari 2018

7. DINKES. PROFIL KESEHATAN TAHUN 2014 KOTA YOGYAKARTA.2015. Available from:

www.depkes.go.id/.../profil/PROFIL KAB.../3471 DIY Kota Yogyakarta 2014.pdf. Diakses Tanggal 29 Januari 2018

8. RISKESDAS. Badan penelitian dan pengembangan kesehatan kementrian RI. 2013. Available from: www.kemenkes.go.id. Diakses Tanggal 12 Oktober 2017

9. Detik Nwes. Kasus Tawuran Pelajardi Yogyakarta Meningkat Di Tahun 2016 (Kamis 29 Desember 2016). Available from: www.news.detik.com. Dikutip 7 Maret 2018

10. Kartini, Kartono. Patologi Sosial. Jakarta: PT Raja Grafindo.2005

11. Muhammad mundzir. Perbedaan Perkembangan Social-Emosional Remaja Yang Tinggal Di Pondok Pesantren (Bahrul Magfiroh) Dengan Remaja Yang Tinggal Di Rumah.[Skripsi]. Malang: UIN Maulana Malik Ibrahim Malang. 2012. Available from: http://etheses.uin-malang.ac.id. Diakses Tanggal 12 Oktober 2017

12. Affandi, Fera Puspita Dewi. Pengaruh Intensitas Pemakaian Facebook Terhadap Perkenbangan Sosial Remaja Di Smp Taruna Dra. Zulaeha.[Skripsi]. Malang: UIN Maulana Malik Ibrahim. 2011

13. Santrock, John W. 2011. Masa Perkembangan Anak, Buku 2, Ed. 2. Jakarta : Salemba Humanika

14. Zahra D dan Fadhila T N. Pengaruh Kematangan Emosi Pada Remaja Ditinjau Dari Pola Asuh Orang Tuan Dan Jenis Kelamin. Riau: Universitas Islam Riau. 2013

15. www. Uir.ac.id (29 mei 2018, 07.29 PM)

16. Curtis, Alexa C. Defining Adolescence, Journal Of Adolescent And Family Health: Vol.7 Article 2. 2015

17. $\quad$ https://scholar.utc.edu/iafh/vol7/iss2/2 (30 mei 2018, $10.00 \mathrm{AM}$ )

18. Rahmawati, Elisa D. Pengaruh Pergaulan Teman Sebaya Dan Konsep Diri Terhadap Kecerdasan Emosional. 2015

19. Hastuti, Novita P. Hubungan Antara Interaksi Teman Sebaya Dengan Penyesuaian Sosial Remaja SMP Negeri 2 Surakarta. 2014

20. Wesley K. Gender Differences In Positive Social-Emotional Functioning. 2011

21. https://onlinelibrary.wiley.com/doi/abs/10.1002/pits.20604 (29 mei 2018, 07.29 PM)

22. Asyhari, Hasyim. Hubungan Peranan Kelompok Teman Sebaya Dengan Kemampuan Perkembangan Psikososial di SMP PGRI Kasihan Bantul. [Skripsi]. Yogyakarta:Universitas Alma Ata; 2017

23. Wahyuni, Nini S. Hubungan Dukungan Sosial Teman Sebaya Dengan Kemampuan Bersosialisasi Pada Siswa SMK Negeri 3 Medan. 2016

24. http://ojs.uma.ac.id/index.php/diversita/article/download/509/359 (29 mei 2018, 07.29 PM)

25. Adriani, Sri N. Pengaruh Interaksi Teman Sebaya Terhadap Kecerdasan Emosional Peserta Didik Di Kelas VIII SMPN 1 Pasaman. 2014

26. http://jim.stkip-pgri-sumbar.ac.id/jurnal/download/1538(29 mei 2018, 07.29 PM)

27. Alligood, Martha R. Pakar Teori Keperawatan. Jakarta: Elsevier. 2011 